\section{Rodney James Clifton}

\author{
H.D. Espinosa • K.T. Ramesh • G. Ravichandran
}

Published online: 6 March 2009

(C) Society for Experimental Mechanics 2009

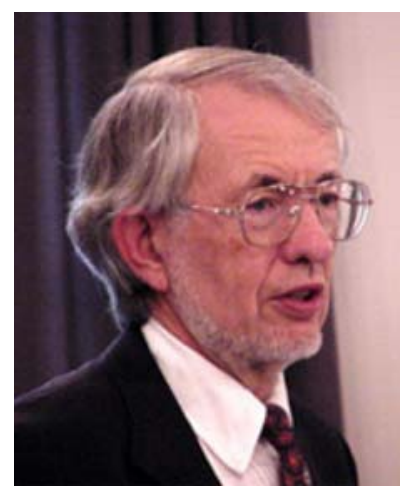

On the occasion of Rodney James Clifton's 70th birthday, a symposium took place on June 8-9, 2007 in Annapolis, Maryland, to celebrate this milestone. Past students and associates attended the event and delivered presentations ranging from wave mechanics to nanomaterials to dislocation modeling to dynamic failure. This special issue, dedicated to Rod, is a compilation of work presented at the symposium.

H.D. Espinosa ( $₫$, SEM member)

Department of Mechanical Engineering, Northwestern University, Evanston, IL, USA

e-mail: espinosa@northwestern.edu

K.T. Ramesh (SEM member)

Department of Mechanical Engineering,

The Johns Hopkins University,

Baltimore, MD, USA

G. Ravichandran (SEM member)

Graduate Aeronautical Laboratories,

California Institute of Technology,

Pasadena, CA, USA
Describing Rod's character and influence on his students, colleagues, collaborators and the mechanics community at large is a major enterprise. A very comprehensive and nicely written biography of Rod appeared in "Symposium on the Dynamic Deformation and Failure Mechanics of Materials, Honoring Professor R.J. Clifton on the Occasion of his 60th Birthday," Journal of the Mechanics and Physics of Solids, Vol. 46, 1998. Below we reprint it with permission from Elsevier.

Here, we attempt to describe Rod's character and influence on his students by quoting shorter versions of statements sent by students who were unable to attend the Annapolis event:

Sam Ranganath, PhD, 1971. "When I joined Brown in 1967, there were very few Indian students at Brown, none in Engineering. I was assigned to work with Rod and I found out how unassuming, kind and patient he was in dealing with a new student just off the boat with an Indian accent. He had the Midwestern small town values of honesty and kindness. Both, me and my wife felt that our experience at Brown was richer because of Rod Clifton."

Prashant Kumar, PhD, 1976. "When I roll back the time calendar fast and reach the first half of 1970s, I still remember many things quite vividly. Rod, sitting on the sixth floor, would figure out how the experiment would move in the basement. He believed in shear logic and would not be bogged down by apprehension of practical problems; and, a great number of his ideas worked. In fact, some of them worked very well. There is another aspect which I appreciate very much. When the research was talked about, we worked like equals, like friends. For example, he would throw an idea and I would not accept it because of some reasons. Then, he would say, "let me throw one more idea, Kumar." If the second idea was not accepted, there would be a third one in the line. He sure 
created a great ambience for research to grow. Now, we all know that this kind of atmosphere has borne many fruits. I wish I was there to say these words myself. I wish that he would continue doing his creative work for a long time. The famous Indian writer Rabindra Nath Tagore started his painting and sketching at the age of 72 . Rod is only 70."

Richard Klopp, PhD, 1987. "Our journey through life is a Brownian motion, where chance encounters result in Heaviside step-function changes in direction, that then alters the ensuing course of one's life. It was a chance encounter with Professor Kalnins at Lehigh which led me to a chance encounter with Brown which led me to a chance encounter with Rod. I am grateful for that, because it has benefited me immensely in the ensuing years. Rod taught us to be inquisitive, to be careful in our arguments, to base them on deep understanding of the fundamentals, and to ground them with simple but elegant real-world laboratory testing. I remain dedicated to that proven approach. For the very hands-on engineer that I am, the alternatives are unthinkable! Thank you, Rod."

George Raiser, $\mathrm{PhD}, 1993$. "I would like to express my sincere thanks to Rod for his dedication to Brown University and his students, past and present. For me, Rod's commitment has enabled the pursuit of a consistently rewarding and gratifying career in science and engineering. It has also given Tiffany and me a happy home life and the ability to give to those less fortunate than ourselves..."

JoAnne Escobar, PhD, 1995. "Dear Rod, Congratulations on your 70th birthday! I want you to know what a positive influence you have been in my life. You have been my teacher, my mentor and my role model. I have so much respect for you as a researcher and educator. But I also have incredible respect for you because of your dedication to family and friends. I recall fondly my time working with you at Brown, and I think of that time often. Even though I have chosen a path outside of academia, I still feel the draw of research. I believe it is because I had you for my mentor, someone who was truly excited by the work and the challenge."

Kris Frutschy, PhD, 1997. "My time working with Rod at Brown University was one of the most rewarding experiences that I have had. Mastering the plate impact experiment - as many know - is a hard-fought, humbling experience, but it reveals secrets of material response unlike any other mechanics experiment. In addition to the strong fundamental science experiments, the camaraderie within the lab was another highlight of my time at Brown-both due to the superb leadership from Rod. We all have a handfull of mentors, who contribute significantly to the person we become. I am lucky to have had Rod as one of those people in my life, and work hard to role model his positive example."
These quotes deeply resonate with each one of Rod's past and current students. He has been a major source of inspiration and guidance to all of us.

Rod has spent his entire professional life at Brown University. Within the Brown community he has served in many capacities, in particular as Dean of the Division of Engineering from 1974 to 1979, again from 1998 to 2003, and now from July 1, 2008 to the present time. Currently he is passionately working on the development of a strategic plan for the creation of a School of Engineering at Brown. This is a challenging enterprise in normal times and much more so in the present economic climate. However, Rod's record of scholarship, service, creativity and leadership makes him the ideal candidate to achieve such an endeavor.

Rod and Mercadee Clifton recently celebrated their 50th wedding anniversary. We join them in celebrating that milestone, and would like to thank Mercadee for her hospitality and kindness over the years. We wish them both a long and healthy life.

In closing, we list Rod's past and current students.

Joel Lipkin (Sandia, Livermore), 1970

Jamie Hsu (GM Research Labs), 1972

Sampath Ranganath (XGEN Engineering), 1971

Ahmed Abou-Sayed (Advantek), 1976

Prashant Kumar (IIT, Kanpur), 1976

Kyung-Suk Kim (Brown), 1980

Chin-Ho Li, 1982

Amos Gilat (Ohio State), 1983

Gad Meir, 1985

Tarek Shawki (UNESCO), 1986

G. Ravichandran (Caltech), 1987

Richard Klopp (Exponent), 1987

K. T. Ramesh (Johns Hopkins), 1988

Wei Tong (SMU), 1991

Horacio Espinosa (Northwestern), 1992

Lewis Grotelueschen, 1993

George Raiser (Medtronic), 1993

Vikas Prakash (Case Western), 1993

Min Zhou (Georgia Tech), 1993

Hai Mei, 1993

Joanne Escobar, 1995

Kris Frutschy (GE), 1997

Sairam Sundaram (GE), 1998

Kevin Duprey (Ensign-Bickford), 1999

Seung-Yong Yang (Korea), 2000

Nitin Bhate (GE), 2001

Vasanth Kothnur (GE), 2002

Zhizhou Zhang (Johns Hopkins), 2006

Stephen Grunschel (Brown), current

Reprinted from "Symposium on the Dynamic Deformation and Failure Mechanics of Materials, Honoring Professor R.J. Clifton on the Occasion of his 60th 


\section{Birthday," Journal of the Mechanics and Physics of Solids, Vol. 46, 1998.}

Rodney James Clifton was born on 10 July 1937 in Orchard, Nebraska, a small town in the northeastern corner of the state. His parents were descended from Europeans who had immigrated to the region in the latter part of the 19th century. His early education was received in small rural schools where he excelled in science, mathematics and athletics. Following secondary school, he enrolled in the program in civil engineering at the University of Nebraska in Lincoln, where he received his BSc degree in 1959.

Upon his graduation from Nebraska, Rod was employed as a structural engineer by the Paxton and Vierling Steel Co. of Omaha. However, his interests were in the fundamental precepts of structural mechanics, and he decided to pursue graduate study in the field. In the fall of 1960, taking advantage of opportunities for graduate study in the USA created as a consequence of the launch of the Soviet satellite sputnik in 1957, he enrolled in the department of civil engineering at Carnegie Institute of Technology, now part of Carnegie Mellon University. He received his PhD in 1964.

Rod's thesis was concerned with the numerical solution of the partial differential equations which describe the propagation of stress waves in solids. The general approach for two space dimensions and time was based on integration of the system of hyperbolic equations along bi-characteristic strips, tangent to characteristic cones. The second-order-accurate method was applied for both elastic and elastic-plastic waves in solids. This work marked the beginning of his long and productive interest in wave propagation in solids.

While at the University of Nebraska, he met Mercadee Bonde and they were married in December of 1958. Their first son Brad was born in 1960, followed by Jeff in 1962, Greg in 1966 and, finally, daughter Ann, born in 1970. Rod and Merc presently have two grandchildren.

Upon completion of his dissertation, Rod inquired at Brown University about the prospects for continuing his research in the Division of Engineering, having become aware of the research tradition there in both plasticity and stress waves. At the time, Brown was the site of one of the national interdisciplinary Materials Research Laboratories, which provided excellent opportunities for short term research visits. (As will be noted below, Rod currently serves as the director of Brown's Materials Research Science and Engineering Center, the direct descendant of the original MRL program.) The senior faculty at Brown concerned with filling research positions were at first curious, and then totally delighted, upon discovering this young person who had written a thesis of consequence in an area of great current interest at Brown, and that he had done so working largely on his own. This work has become broadly known in the area and is still cited frequently today.
Rod and his young family arrived in providence in January of 1964, and he began a very productive period of research which established the framework for much of the work done subsequently in the area which has become known as dynamic plasticity. He developed solution procedures for analyzing plastic wave propagation, especially combined-stress plastic waves. A beautiful discussion entitled 'An analysis of combined longitudinal and torsional plastic waves in a thin-walled tube' appeared in the proceedings of the 5th US National Congress of Applied Mechanics held in Minnesota in 1966. Then, with his first PhD student, Joel Lipkin, he carried out the corresponding experiment. This work was reported in 'An experimental study of combined longitudinal and torsional plastic waves in a thin-walled tube' which appeared in the proceedings of the 12th International Congress of Theoretical and Applied Mechanics in 1968. This blend of creative experimental investigation with sound analysis was to become the hallmark of his work in the field. Among the many innovations in experimental dynamic plasticity which were developed in his laboratory are the pressure-shear plate impact configurations, which opened the way for the broad study of combined-stress plastic waves of one-dimensional strain on the basis of interpretable experiments, and the transverse displacement interferometer for detecting lateral motion of a specimen surface in the plate impact apparatus. Both the standard and the pressure-shear configurations of the plate impact apparatus were also modified to measure plane strain fracture toughness of steels under high rates of loading, the nucleation and propagation of shear bands in metals, the pressure-shear characteristics of lubricants at high rates of deformation, the high-rate response of fragmented brittle materials, and nucleation of failure in brittle polycrystalline ceramics. In each of these situations, novel experimental procedures, supported by sound analysis or numerical modeling, led to significant advances.

Largely through his association with Terra Tek Inc. of Salt Lake City, first as a consultant and subsequently as a member of the Board of Directors, he also made important contributions to the area of hydraulic fracture of geological materials and secondary oil recovery technology. His contributions included both fundamental studies on applications of fracture mechanics and the development of commercial software for prediction of hydraulic fracturing patterns around bore holes.

Over the years at Brown, more than 25 graduate students have completed their $\mathrm{PhD}$ thesis research under his direction. He is well-known for the close personal attention given to the work of each student and for fostering an independent and discriminating point of view within each student over the course of his or her work. These former students, who now contribute at leading universities, research laboratories and industrial laboratories throughout 
the USA and abroad, are having a major impact on the area of experimental mechanics.

In addition to his research contributions, Rod has been very generous with his time in service to his university and profession. Through his leadership and sound judgment, he has had a profound influence on the programs in the Division of Engineering at Brown over the years. He served as Chair of the Engineering Executive committee (197479), as Director of the Central Facility for Mechanical Testing (1980-86), on the University Research Council (1987-91), as Principal Investigator and Director of the NSF Materials Research Group (1989-96), as Principal Investigator and Director of the NSF Materials Research Science and Engineering Center (1996-date), and on many other committees and panels. He has also served as Associate Editor of the Journal of Applied Mechanics (1981-88), on the Board of Directors of the Society of Engineering Science (1977-83), president of the Society of Engineering Science (1982-83), on the editorial advisory board of the Journal of the Mechanics and Physics of Solids (1982-date), on the Board of Directors of the NSF Institute for Mechanics and Materials (1992-date), on the mechanical engineering peer committee of the national Academy of Engineering (Vice Chair 1995, Chair 1996), and on advisory boards of several federal agencies.

For his many contributions in both research and service, Rod has been recognized by election as a Fellow of the American Academy of Mechanics, through receipt of the
ASME Melville Medal (joint with K. S, Kim), the SES Prager medal, the best paper award of the ASME Tribology Division, (joint with K. T. Ramesh), by the Distinguished Alumni Award of Carnegie Mellon University, and by election to membership in the National Academy of Engineering.

Most of the foregoing information has been drawn from the public record, where Rod's impressive professional accomplishments are evident for all to see. However, the full dimension of Rod Clifton is most appreciated by those who have had the privilege of a direct association. He is devoted to his family and has been tireless in quest of their happiness and interests. He has been active in his church and generous on behalf of its causes, including Habitat for Humanity and others. Within the Division of Engineering at Brown, he has had a long-standing interest in the undergraduate programs of instruction, often volunteering for the most difficult teaching assignments in an effort to improve the educational experiences of the students. The door of his office has always been open to students who require extra help to surmount some barrier, and it is not unusual to find students waiting their turn outside his office door long after closing hours in the department. Those who have had the good fortune of having been a faculty colleague have benefited immeasurably from Rod's leadership, sound judgment and enormous efforts for the common good, and have appreciated his good humor and collegiality. $\mathrm{He}$ is a model of integrity and dedication. 